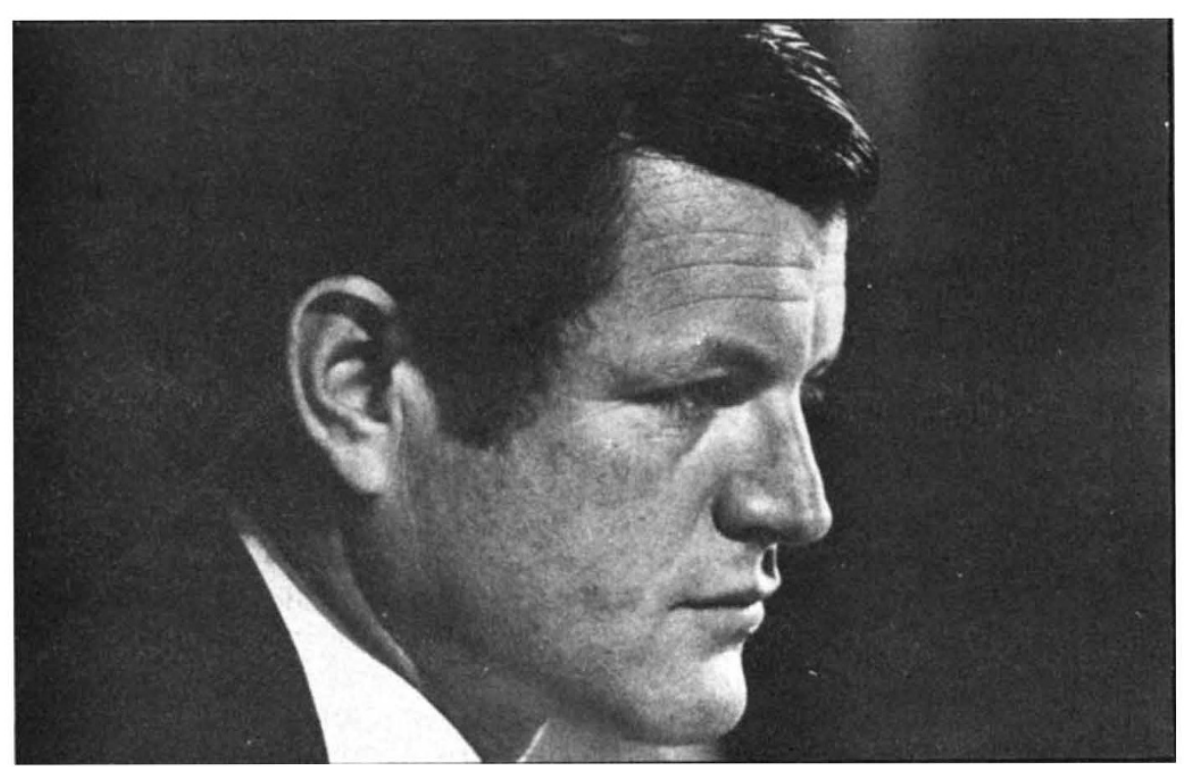

\section{Guinea-pig charters}

A number of ethically questionable research practices brought to light recently in the United States have led to calls for tighter control of human experimentation. Colin Norman discusses some of the regulations which have been proposed and their effect on research.

MANY American scientists hoping to conduct experiments on their fellow men and women will soon have to submit the ethics of their research to intense scrutiny by a raft of committees before they can get any funds. Some will then find people constantly looking over their shoulders while they carry out their experiments, others will find whole avenues of research shut off by the federal government or by state and local laws. In short, the traditional freedom of the scientist to organise his work is about to see drastic changes.

Human experimentation, like presidential power, has recently been a subject of national debate thanks to some widely publicised examples of ethical bankruptcy. Such examples include allegations that a number of poor black men who were known to have syphilis were left untreated so that the course of their disease could be monitored, that prisoners have been subjected to painful and essentially pointless medical experiments and that several children have been left mentally maimed by psychosurgery. The allegations have led to strident demands for more control over human experimentation, and the vocal anti-abortion lobby in the United States has also left its mark in the area of foetal research.

The controls have come from four directions: Congress, the Department of Health, Education and Welfare (HEW), state and local governments,
At the Congressional level, a bill has been passed and signed into law by former President Nixon which sets up an eleven-member national commission on human experimentation whose duty will be to draft a set of regulations to protect human subjects of biomedical and behavioural research. The commission, which should be established later this month, has been given two years to complete the task and has been asked to concentrate its attention on areas such as research with children, prisoners and the mentally disabled, where ethical and legal problems abound.

As for research on pregnant women and foetuses, the bill-a measure inspired by Senator Edward Kennedy called the National Research Act-imposes a four-month ban on federal support for research involving foetuses with beating hearts, before or after an induced abortion. While the ban is in effect, the commission will draw up regulations governing such research.

Meanwhile, HEW has been moving independently to strengthen controls over human experimentation supported by the National Institute of Health (NIH), the National Institute of Mental Health (NIMH), the Food and Drug Administration (FDA) and other HEW agencies.

The department has already imposed a blanket provision that human experimentation will only be supported at institutions which have established review committees to scrutinise the ethics of individual studies before application is made for funds, and it is now in the middle of devising extra protection for children, pregnant women, foetuses, prisoners and mental patients Last week, HEW proposed some tough regulations in that regard. and the courts.
Senator Kennedy: inspired anti-foetal research bill.

At the state and local level, several laws have been passed which impose restrictions on foetal research, the most prominent being a recent move in Massachusetts to outlaw research on living foetuses, before or after abortion. While the federal regulations would simply cut off funding for such research, the state laws would make some types of foetal research a crime punishable by a stretch in jail.

As for the courts, the whole concept of legal consent to take part in research as it applies to children and mental patients is under challenge in at least two cases, and in Boston four doctors are now awaiting trial on charges arising from some foetal research they conducted in 1971. Thus, as is common practice in the United States, the courts are likely to define some of the parameters of social policy.

All these attempts to regulate the practice of human experimentation involve a delicate balancing act by weighing potential benefits to society from medical research against the possible risks to those who take part. It is a balancing act which has its roots in the preamble to the United States Constitution, which states that the Constitution is designed to "promote the general Welfare, and to secure the Blessings of Liberty".

According to $\mathrm{Dr}$ Donald $\mathrm{T}$. Chalkley, chief of NIH's Instutional Relations Branch, which has been drafting the HEW regulations, the real problem is that "we have a public concept of research that is based on fiction--on Clockwork Orange or Lord of the Flies experiments--but $90 \%$ of the research involves no more than the taking of a blood sample". This public concept is catusing legislators to pass unduly restrictive laws, such as the blanket ban on foetal research.

Although stopping well short of imposing a flat ban on research involving living foetuses, HEW's proposed regulations would severely restrict such studies, and outlaw some kinds of research entirely. In short, such experiments would be subjected to three separate ethical checks, and they would have to be confined to a very narrow range of experiments in order to qualify for HEW support.

Ruled out would be a wide range of experiments on foetuses in utero, before they are aborted. Such prohibitions are also embodied in the Massachusetts foetal research law, and when that law was being debated, many scientists warned that the effect would be to stop a number of valuable research projects, and possibly to place future generations of children at risk. 
The prohibition would prevent drugs or vaccines being administered to pregnant women about to undergo abortions in order to see whether they cross the placenta into the foetus. For some substances, such as rubella vaccine, such knowledge is essential because of the dangers that foetal abnormalities may be caused if the substance does cross the placenta. Dr Chalkley acknowledged in an interview last week that banning such research could place children at risk, but he pointed out that the problem is to balance the individual rights of the foetus and its mother against the potential promotion of the general welfare of children, both of which are equally protected by the Constitution.

HEW also chose to draw the line against foetal research in utero, which is not designed to benefit the mother or that particular foetus, because if the foctus is placed at risk by such experiments, it would be very difficult for the mother to change her mind about going through with the abortion.

It is worth pointing out, however, that although the HEW proposals would permit experiments designed to benefit the mother or the foetus, they would rule out control experiments because they ban all non-therapeutic studies on living foetuses.

If the setting of regulations governing foetal research is fraught with difficulty, the situation regarding research on children is even more difficult. The benefits from paediatric research are obvious, but the ethical and legal problems are also legion, and HEW, which has been trying to set some regulations in this area for the past couple of years has so far been unable to do so.

The problem is essentially two-fold. First, there is the difficulty of defining what kinds of research should be permitted and what should be outlawed. As Chalkley put it last week, if you shut off an area of research now because the potential benefits are outweighed by the risks, you may be opening the door to new diseases. And second, there is the problem of getting informed consent from minors.
Can a parent or guardian legally and morally consent to have his or her child take part in a research project which might involve some risk, but which will not benefit the child directly? A law suit, filed against the University of California by an attorney, James R. Nielsen, contends that no "invasive" medical research procedures should be practised on a normal healthy child unless they hold potential direct benefit for the child.

Again, if research directly beneficial to the child is allowed but every other type of paediatric research is outlawed, one effect would be to prevent the use of control groups in any such experiment. Clearly, the issue of human experimentation is far from dead, and verbal battles will be fought on a variety of fronts. But at present the course of events at the federal level is far from clear.

The most likely scenario, is that HEW (open for comments until November) will put its regulations into effect next year, and the commission will suggest amendments in 1976.

LAST month, the US Department of tion of the proposed regulations deals more, HEW is proposing that experiHealth, Education and Welfare (HEW) with research on pregnant women and mental procedures which would terproposed some tough regulations foetuses. First, HEW is suggesting that minate the heartbeat or respiration of governing research on prisoners, men- yet another ethical check be applied to the foetus should be banned, but it tal patients, pregnant women and foe- such studies from an Ethical Advisory stops short of calling for complete tuses. Designed to protect the rights of Board, to be established in every HEW cessation of studies on foetuses with those being experimented upon, the agency funding foetal research. beating hearts.

regulations would establish a number of These boards, which would consist of - As far as research on prisoners is ethical checks on research projects, and members appointed by the Secretary of concerned, HEW suggests that an even ban some types of experiments en- HEW, from outside the government Organisation Review Committee and a tirely.

First, under regulations already in such studies after they have been effect, every institution in receipt of approved by Organisational Review funds from HEW must establish an Committees.

Organisational Review Committee, All research involving foetuses in composed of people from a variety of utero on pregnant women would, howoccupations, to review research proto- ever, be banned unless (a) "the purpose cols involving human experimentation of the activity is to benefit the particubefore they are submitted to HEW for lar foetus or to respond to the health funding. This first ethical check will needs of the mother", or (b) the reweigh the benefits to be derived from search is aimed at "evaluating or imthe experiment against the risks to those proving methods of prenatal diagnosis, taking part, and it will also ensure that methods of prevention of premature adequate provision is made for obtain- birth, or methods of intervention to offing informed consent from the subjects. set the effects of genetic abnormality or

In addition, HEW is now proposing cengenital injury", in which case, "the that another committee-the Consent activity [must be] conducted as part of Committee-be established at the insti- (but not prior to the commencement of) tutional level to provide continuing a procedure to terminate the pregethical review of experiments involving nancy". The mother's consent would be prisoners, mental patients and pregnant required for such research, and the rewomen. This committee will oversee the searcher should have no part in deteractual selection of subjects, make sure mining either the timing or method of that they consent to take part without abortion or the viability of the foetus. coercion and after having been fully informed of the risks, and that they are able to opt out at any stage if they no longer want to take part. The new HEW proposals would also impose the following restrictions:

As for research on abortuses, the proposed regulations would require that relevant animal studies first be completed, that the mother's (and if possible the vital functions of the abortus are Branch, Division of Research Grants, Consent Committee should provide adequate protection for research subjects, by making sure that prisoners are offered no special inducements or threats to make them take part. A preamble to the regulations specifically rejects the notion that since prisoners have little freedom of choice in anything, they are incapable of freely giving their consent to take part in research projects.

- Involuntarily detained mental patients pose a slightly more difficult problem. The regulations, however, would permit research on such people provided that the study is "related to the etiology, pathogenesis, prevention, diagnosis, or treatment of mental disability or the management, training, or rehabilitation of the mentally disabled and seeks information which cannot be obtained from subjects who are not institutionalised mentally disabled".

In other words, HEW is attempting to rule out the use of mental patients for studies unrelated to their mental illness.

The proposed regulations are availthe father's) consent be given, and that able from the Institutional Relations - By far the most controversial por- not artificially maintained. Further- NIH, Bethesda, Md. 20014, USA. 